\title{
Composition Optimization of Glass-Like Casing and Its Novel Application in Mending Instable Borehole Wall
}

\author{
Zhi-jun Li, ${ }^{1}$ Yu Wang, ${ }^{1}$ Bao-lin Liu, ${ }^{1}$ and Chun Yang ${ }^{1,2}$ \\ ${ }^{1}$ Key Laboratory on Deep Geodrilling Technology of the Ministry of Land and Resources, \\ China University of Geosciences, Beijing 100083, China \\ ${ }^{2}$ Sinomine Resource Exploration Co., Ltd, Beijing 100083, China
}

Correspondence should be addressed to Yu Wang; wangyu203@cugb.edu.cn

Received 21 August 2014; Revised 2 January 2015; Accepted 7 January 2015

Academic Editor: Hanlie Hong

Copyright (c) 2015 Zhi-jun Li et al. This is an open access article distributed under the Creative Commons Attribution License, which permits unrestricted use, distribution, and reproduction in any medium, provided the original work is properly cited.

\begin{abstract}
A glass-like casing was developed to mend the instable borehole due to its great similarities in compositions and structure. In order to boost the casing's mechanical properties and lower its cost, different wt $\%$ additions of aluminum and quartz sand are added into the composition. Based on the outcomes of differential scanning calorimeter (DSC), it is suggested to be sintered at the temperature of $700^{\circ} \mathrm{C}$. The results of X-ray diffraction (XRD) show that aluminum and $\mathrm{SiO}_{2}$ are its main crystalline phases. Its compression strength and the tensile strength range 5-14 Mpa and 0.5-4.5 Mpa, respectively, with the relative densities of between $1.00 \mathrm{~g} / \mathrm{cm}^{3}$ and $1.19 \mathrm{~g} / \mathrm{cm}^{3}$. In the end, a glass-based formula with $30 \mathrm{wt} \%$ aluminum and $40 \mathrm{wt} \%$ quartz sand is developed and experimentally applied.
\end{abstract}

\section{Introduction}

Nowadays, wellbore instability has severely influenced the drilling efficiency [1]. In the past, the casing running is most frequently used to protect the well from being damaged. Mostly, however, the holes will be damaged at some certain parts; therefore, there is little point in practically mending the whole borehole wall. However, in most practical cases, the casing running will be applied from hole's bottom to the orifice, a huge waste of steel casing. In order to reduce the huge cost, a novel technology of hot melting casing is developed. The original concept of this technology is derived from Subterrene drilling, which makes holes in rocks and soils through progressive melting instead of mechanical chipping. During the process of the Subterrene drilling, a glass-like casing can be formed according to the research conducted by Los Alamos National Lab [2-5].

However, there are few attempts that have been made to research the composition as the glass-like casing. It is also a new attempt that combines the advanced material with the earth science-especially in geological engineering. Therefore, in order to make matters more understandable, a rough sketch Figure 1 is sketched to show the process of the casing forming through the technology of hot melting $[5,6]$.

As is shown in Figure 1, the heat is primarily generated from a center that is made of Carbon-Carbon. The heat is sequentially transferred to the crust and the glass-like material. When the glass-like material is heated to the transition temperature $\left(T_{q}\right)$, it gradually gets transformed into liquid with certain liquidity so that the glass-like casing can be formed. However, the thermal diffusivities of the glasslike casing and the borehole wall are different, leading to a temperature gap at their interface, which makes the glass-like casing forming a reality [5].

In this process, the heating temperature of the composition should be researched first since it has close relationships with the heating temperature and the design of other parts of the device. A relatively approximate melting temperature can be easily determined through the results of the DSC of the compositions.

This heating temperature is the key to optimize the makings of other components of the hot melting machine, especially the coating of the heater shell. This heating temperature is primarily related to the composition's fluidity. 


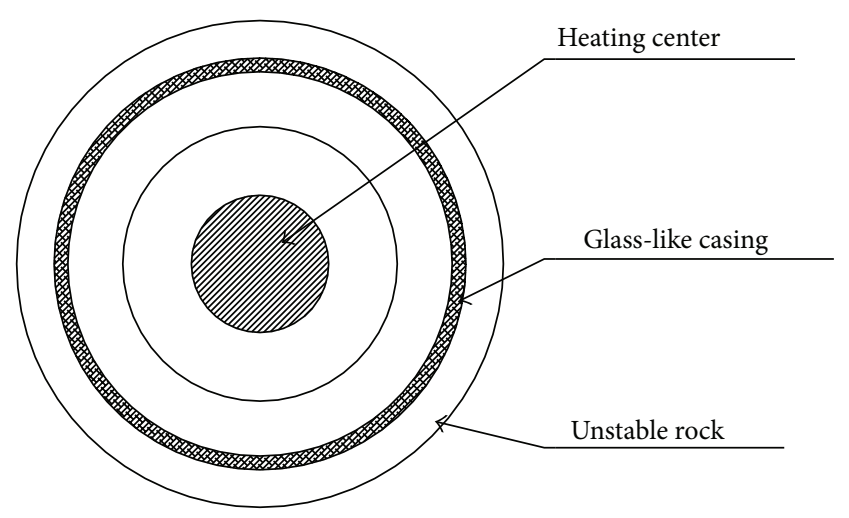

FIGURE 1: Heat distribution during developing a hot melting casing.

If the fluidity is lower enough, the glass-like composition will consequently stick to the shell. As a consequence, a coat has to be made onto the shell to prevent it from being damaged. Therefore, the research on the properties of the glass ceramic can be of great significance when it comes to the overall design of this technology.

In this paper, a composition that is similar to the shale has been developed. It is the first time to apply this glass-like casing to mend the broken borehole wall and many problems have come into being [7]. For example, in field, there is commonly no time to make the material insulated for a long time; therefore, it is highly suggested to cool it down in one minute. This makes the heat treatment more complicated to be under control, especially when the heat treatment happens underground. In order to make experiments conditions similar to the actual field conditions as much as possible, the heat insulation has been gave up, and the material has been cooled down directly in air. Furthermore, the glass-like casing is formed in an irregular shape, making some researches, the electron probe, for example, inaccurately unavailable. Although it is uneasy to deal with the natural problems above, the influence of different additives on the compositions in terms of heating stability, crystal phase growth, and field application has also been researched [8].

\section{Experiments}

In terms of any material, lower cost shall be an essential requirement for its future application in field. The composition provided by Zhuhai Xuanyang Limited is selected to be the raw material (RM). Due to the raw material's poor toughness and relatively high cost (RMB140 per $500 \mathrm{~g}$ ), different wt $\%$ additives, aluminum (Al, RMB15 per $500 \mathrm{~g}$ ), and quartz sand (QS, RMB 0.09 per $500 \mathrm{~g}$ ) are added into the raw material. The components of different compositions are shown in Table 1.

There are some advantages both in $\mathrm{Al}$ and in quartz sand as for a high-quality additive, due to not only its lower cost but also good toughness [9]. As a matrix in bulk metallic glass due to its good performance in good toughness, the addition of $\mathrm{Al}$ also predominately contributes to the mechanical properties

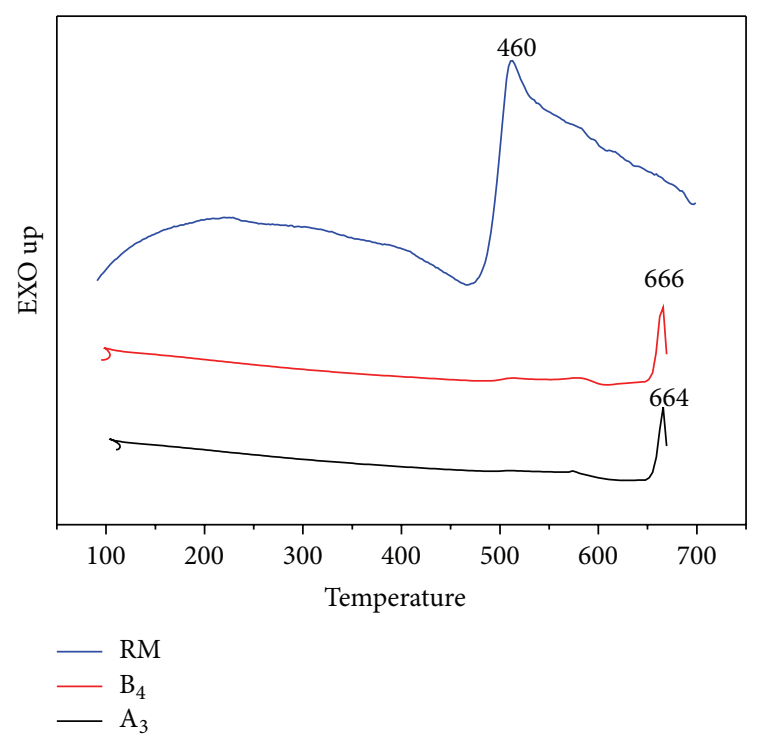

Figure 2: DSC results of samples RM, $\mathrm{A}_{3}$, and $\mathrm{B}_{4}$, respectively.

TABLE 1: Components of different compositions for making a borehole casing.

\begin{tabular}{lccc}
\hline Sample & $\mathrm{RM}(\mathrm{wt} \%)$ & $\mathrm{Al}(\mathrm{wt} \%)$ & $\mathrm{QS}(\mathrm{wt} \%)$ \\
\hline $\mathrm{A}_{1}$ & 90 & 10 & 0 \\
$\mathrm{~A}_{2}$ & 80 & 20 & 0 \\
$\mathrm{~A}_{3}$ & 75 & 25 & 0 \\
$\mathrm{~A}_{4}$ & 70 & 30 & 0 \\
$\mathrm{~B}_{1}$ & 70 & 10 & 20 \\
$\mathrm{~B}_{2}$ & 50 & 20 & 30 \\
$\mathrm{~B}_{3}$ & 40 & 30 & 30 \\
$\mathrm{~B}_{4}$ & 30 & 30 & 40 \\
\hline
\end{tabular}

of the compositions in our research [8]. Similarly, quartz sand has good performance in wear resistance and lower cost [10].

XRD was applied to analyze the crystal phase because whether the crystal phase is beneficial for practical use or not is still unknown. For example, in our research, the crystal phase plays a positive role because it can boost material's mechanical properties while having little influence on fluidity. In addition, in order to figure out the influence of adding different additives on the crystalline phase growth, the scanning electron microscope (SEM) was also applied. For its future practical use, the optimized composition was applied in a model prototype [7].

\section{Results and Discussions}

In order to heat the composition at a proper temperature, the DSC was applied to find out the specific $T_{g}$. The results are plotted as in Figure 2 and Table 2.

The results show that the $T_{g}$ increases with the add-in $\mathrm{Al}$, while the melting point decreases in terms of $\mathrm{RM}$ and $\mathrm{A}_{3}$. That mainly accounted for the lower melting point of $\mathrm{Al}-660^{\circ} \mathrm{C}$, which is so close to the $T_{g}$ of $\mathrm{A}_{3}$ and $\mathrm{B}_{4}$. So the add-in $\mathrm{Al}$ makes great contribution to lower the melting 


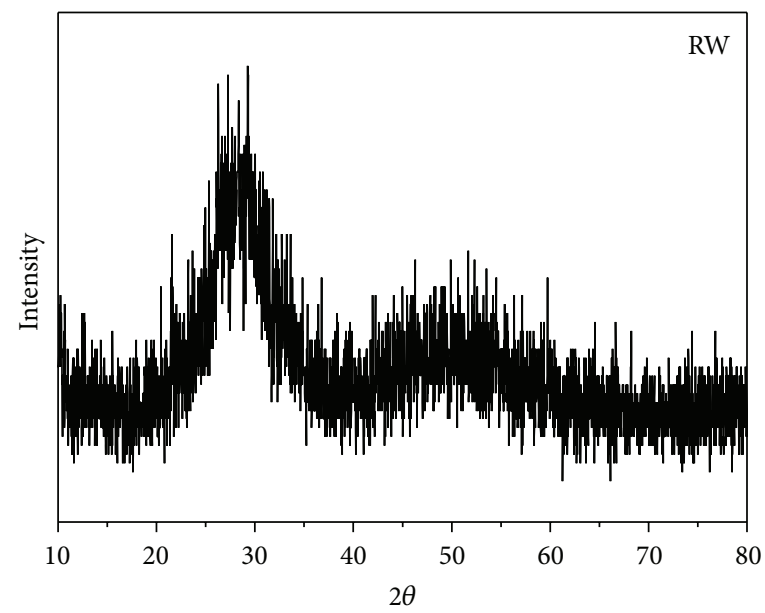

(a)

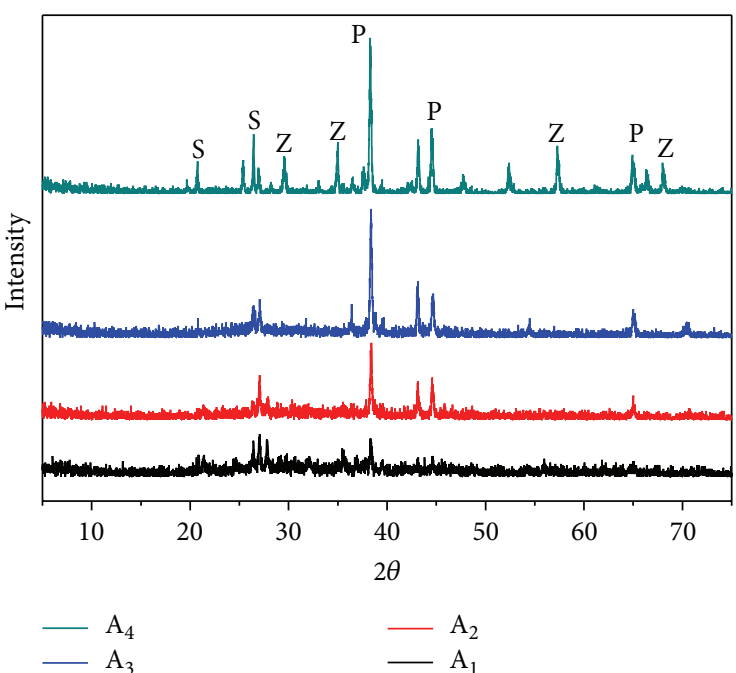

(b)

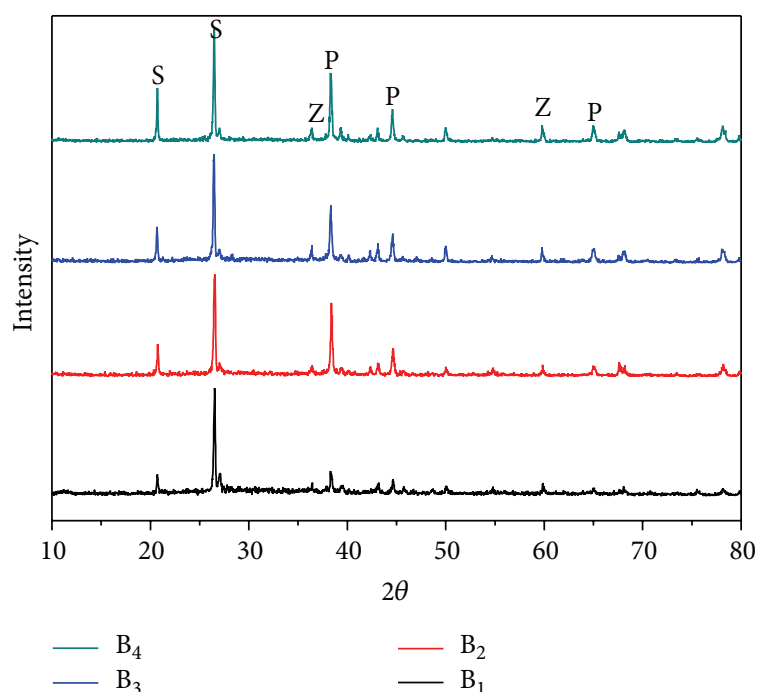

(c)

FIGURE 3: XRD patterns of different samples under the same condition, marked (a), (b), and (c).

TABLE 2: $T_{g}$ and melting point performance of different compositions.

\begin{tabular}{lcc}
\hline Samples & $T_{g}\left({ }^{\circ} \mathrm{C}\right)$ & Melting point $\left({ }^{\circ} \mathrm{C}\right)$ \\
\hline RW & 460 & 770 \\
$\mathrm{~A}_{3}$ & 657 & 664 \\
$\mathrm{~B}_{4}$ & 657 & 666 \\
\hline
\end{tabular}

points of the compositions. The results above make great sense in figuring out a proper heating temperature $\left(700^{\circ} \mathrm{C}\right)$. In addition, $7^{\circ} \mathrm{C} /$ second was selected to heat the composition, the maximum heating rate that our device can reach.

However, whether the add-in Al or the newly generated crystal can improve the composition's physical properties is still unknown. Therefore, the XRD (shown in Figure 3) is performed on the samples.

The results in Figure 3(a) show that there is no typical crystal phase in RM, though it has a trend to form a peak, which is one of the typical properties of glass. However, the composition with add-in Al performs well in crystal phase (Figure 3(b)). Three different peaks represent different compounds phases: label " $\mathrm{P}$ " stands for the distribution of $\mathrm{Al}$, label " $\mathrm{S}$ " stands for the distribution of $\mathrm{SiO}_{2}$, and label " $\mathrm{Z}$ " stands for the distribution of $\mathrm{ZnO}$. This actually proves that the add-in Al contributes to the appearance of the crystal phases, including $\mathrm{ZnO}$ and $\mathrm{SiO}_{2}$, both of which did not actually appear in the RM.

After QS is added into the composition, the "S" peak greatly goes up. Similarly, this is mainly because $\mathrm{SiO}_{2}$ is the main making of the QS. At the same time, the " $Z$ " peak goes down with the addition of QS. However, whether the newly appearing crystal phase is beneficial for the composition's mechanical properties or not is still unknown so far.

In order to make a better comparison to the rock, the Brazilian Formula experiment for testing the tensile strength of the rock was applied to the samples of three. Since the tensile strength is far greater than the compressive strength 


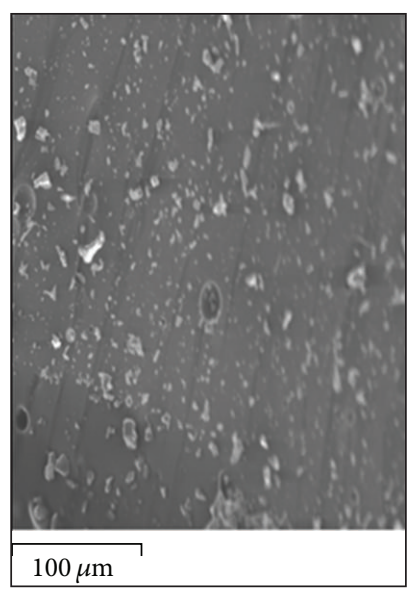

(a)

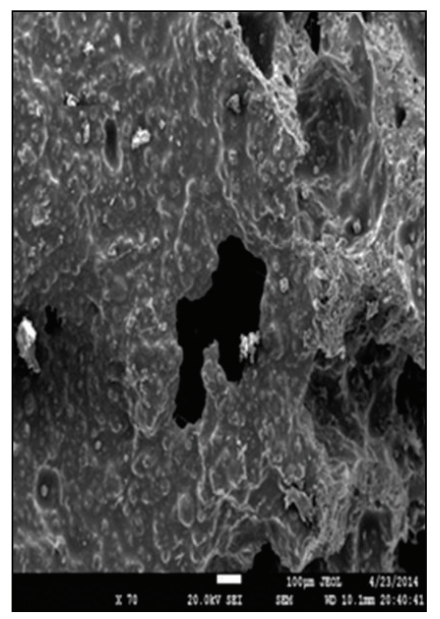

(d)

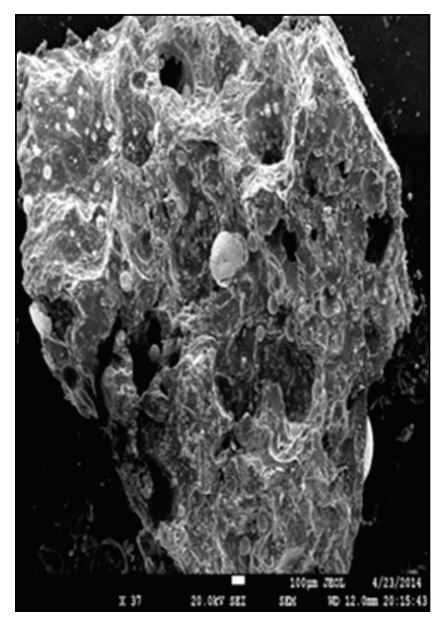

(g)

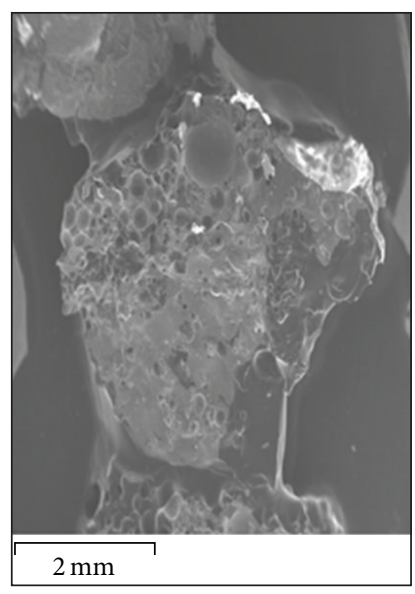

(b)

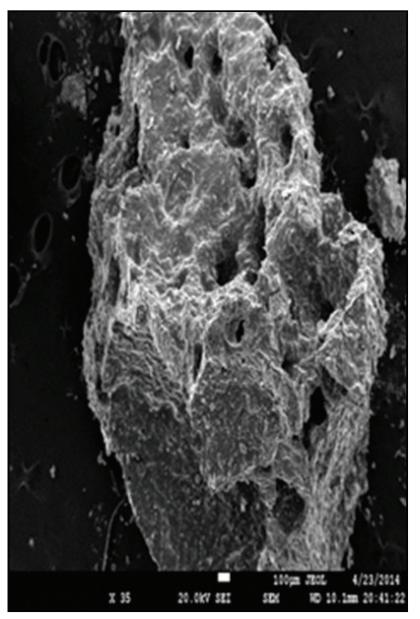

(e)

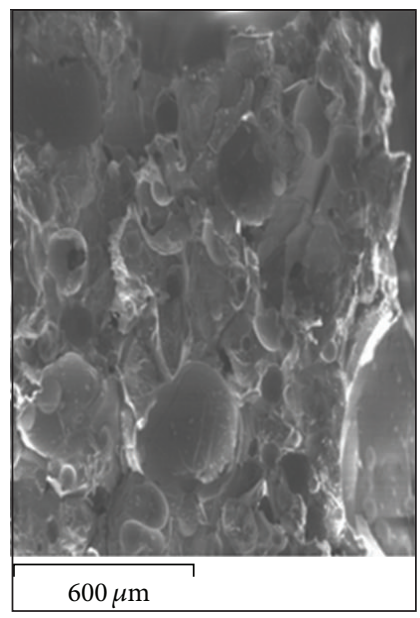

(h)

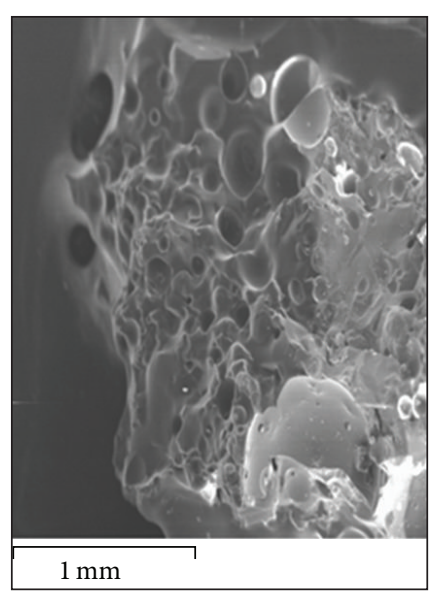

(c)

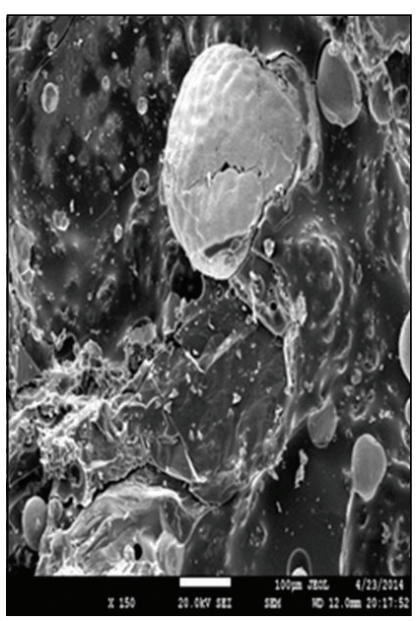

(f)

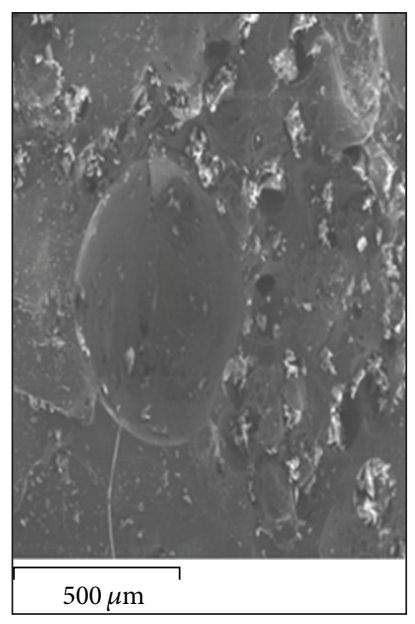

(i)

Figure 4: SEM micrographs of (a) RM, (b) $A_{1}$, (c) $A_{2}$, (d) $A_{3}$, (e) $A_{4}$, (f) $B_{1}$, (g) $B_{2}$, (h) $B_{3}$, and (i) $B_{4}$. 
TABLE 3: Physical and mechanical characteristics of the samples.

\begin{tabular}{lccc}
\hline Samples & $\begin{array}{c}\text { Bulk density, } \rho \\
\left(\mathrm{g} / \mathrm{cm}^{3}\right)\end{array}$ & $\begin{array}{c}\text { Compressive strength } \\
(\mathrm{Mpa})\end{array}$ & $\begin{array}{c}\text { Tensile strength } \\
(\mathrm{Mpa})\end{array}$ \\
\hline $\mathrm{RW}$ & 3.20 & 6.5 & 1.5 \\
$\mathrm{~A}_{1}$ & 1.11 & 5.7 & 1.3 \\
$\mathrm{~A}_{2}$ & 1.03 & 6.0 & 1.4 \\
$\mathrm{~A}_{3}$ & 1.10 & 10.1 & 2.1 \\
$\mathrm{~A}_{4}$ & 1.12 & 6.9 & 1.7 \\
$\mathrm{~B}_{1}$ & 1.03 & 5.7 & 0.6 \\
$\mathrm{~B}_{2}$ & 1.12 & 11.3 & 2.8 \\
$\mathrm{~B}_{3}$ & 1.16 & 11.5 & 4.2 \\
$\mathrm{~B}_{4}$ & 1.19 & 14.0 & 4.4 \\
\hline
\end{tabular}

of the rock, the sample at this condition is always in tension rather than compression failure of damage. This is the Brazilian method to test the tensile strength of brittle material mechanics theory.

The results in Table 3 show that the bulk density generally decreases with the add-in $\mathrm{Al}$ and $\mathrm{QS}$, no matter for sample $\mathrm{A}$ or $\mathrm{B}$. This is probably associated with the large porosity rates of the compositions. The results shown in the following SEM are also another proof to illustrate this. The compressive and tensile strength are roughly boosted by the addition of $\mathrm{Al}$ and QS. This is another proof that shows that the newly generated crystal definitely contributes to the increased the values of the compositions.

The outcomes of SEM (Figure 4) suggest that samples A and $\mathrm{B}$ have much more porosity in comparison to RM. The lower bulk density, representing higher porosity, is accounted for as a consequence of different compositions and physical characteristics of the viscous flow during the heat treatment [11]. Interestingly, the overall rate of pores goes up at first and then down at the point of adding in $25 \mathrm{wt} \% \mathrm{Al}$. The increased pore rate is associated with the difficult in releasing $\mathrm{CO}_{2}$, due to the lack of insulation or the deformation of calcite (probably from the RM). The add-in $\mathrm{Al}$ also boosts the process of deformation, causing $\mathrm{CO}_{2}$ encapsulated by the crystal of $\mathrm{Al}$ [12-14]. When the $\mathrm{Al}$ is the only additive added into the composition, the interconnected pore is characterized by layered shape with the same size.

However, the layered shape of the pore is broken into more irregular ones with the add-in QS, reducing the overall porosity rate of the composition. This greatly contributes to the improved bulk density and mechanical properties. As is shown in Figure 4(i), the pore line is obscure to be seen, of which the mechanical properties perform best among the all compositions.

The results of Table 3 and Figure 4 show that, with the increasing add-in $\mathrm{Al}$, both of the compressive and tensile strength perform better, with the maximum $14.0 \mathrm{Mpa}$ and 4.4 Mpa in $\mathrm{B}_{4}(30 \% \mathrm{RW}, 30 \% \mathrm{Al}$, and $40 \% \mathrm{QS})$. In addition, its cost is relatively lower than others due to the greatest proportion of add-in QS, whose cost is comparatively lower than $\mathrm{Al}$ and RW. Taking the compressive and tensile strength and the lower cost together, the $\mathrm{B}_{4}$ with $30 \% \mathrm{Al}, 30 \% \mathrm{RW}$,

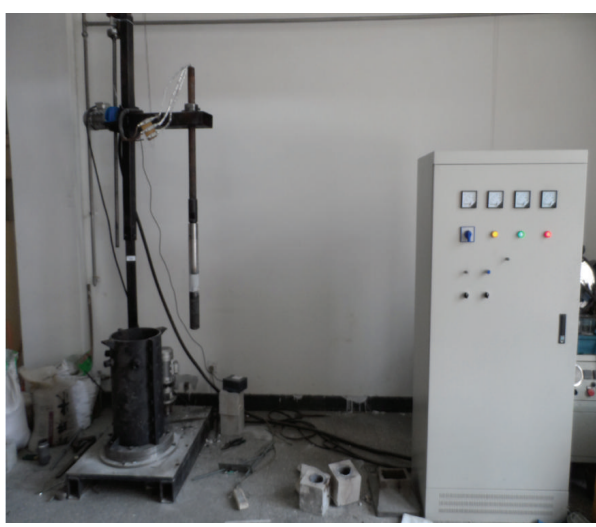

FIGURE 5: Device for conducting this laboratory experiment.

and $40 \%$ QS is eventually selected as the composition to be initially used in laboratory experiment.

\section{Practical Application in Laboratory Experiment}

In order to check whether the composition of the sample $\mathrm{B}_{4}$ can be successfully applied in practice, as has been suggested as the most excellent candidate up to now, a device intended for this novel application was developed (shown in Figure 5). The composition was performed in different borehole wall using this device.

The laboratory experiment was conducted on a novel machine that was developed by our team. A carbon-carbon $(\mathrm{C} / \mathrm{C})$ was applied to generate heat, which is the original source for heating our selected compositions. The heat head consists of heat element of high strength graphite and external shell of GH742 alloy. The high strength graphite can work under $1200^{\circ} \mathrm{C}$. Although the carbon-carbon composite is characterized by high strength and large thermal conductivity, it performs badly in resisting high temperature oxidation. Due to the special experiment equipment, the experimental test can be currently finished in our lab; however, the theoretically compressive and tensile pressure can be repeatedly obtained by the ordinary equipment to test mechanical properties.

The results of Figure 6 indicate that the compositions can be successfully used to form a glass-like casing with certain strength, no matter in rock or soil. However, many problems need to be solved through our further study, including the influences of heat treatment and components of compositions on its physical and mechanical properties.

\section{Conclusions}

Based on the researching results, the composition of sample $\mathrm{B}_{4}(30 \mathrm{wt} \% \mathrm{Al}+40 \mathrm{wt} \% \mathrm{QS}+30 \mathrm{wt} \% \mathrm{RM})$ has turned out to be a high potential for making glass-like casing. The add-in $\mathrm{Al}$ and QS contributes to the lower cost and the highquality mechanical properties of the compositions due to the newly generated crystal, which has a positive influence 


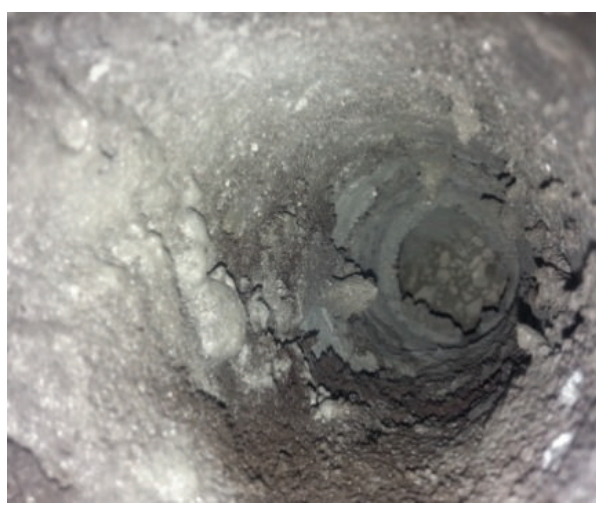

(a)

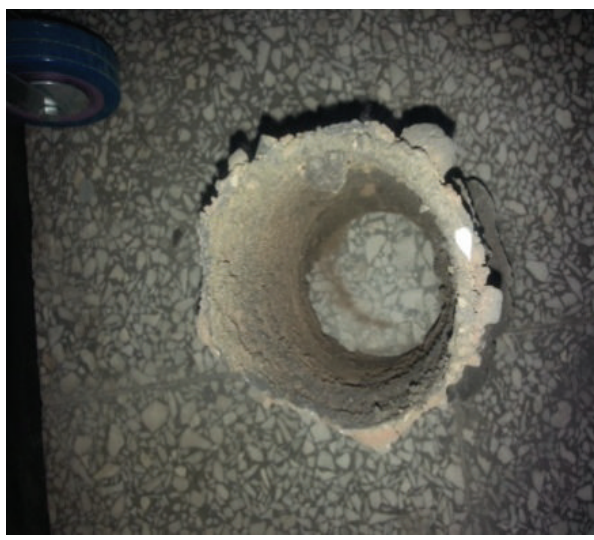

(c)

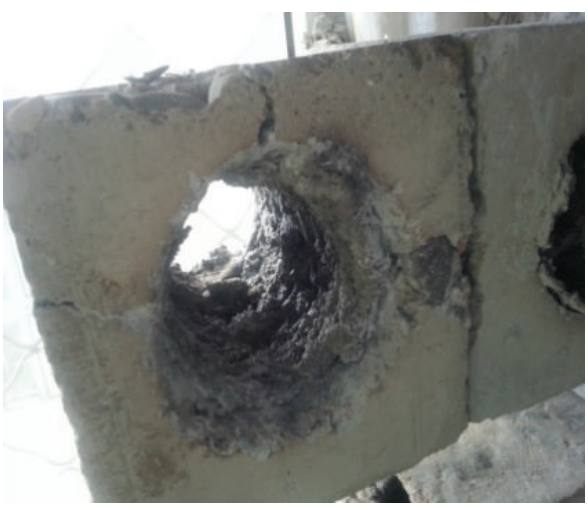

(b)

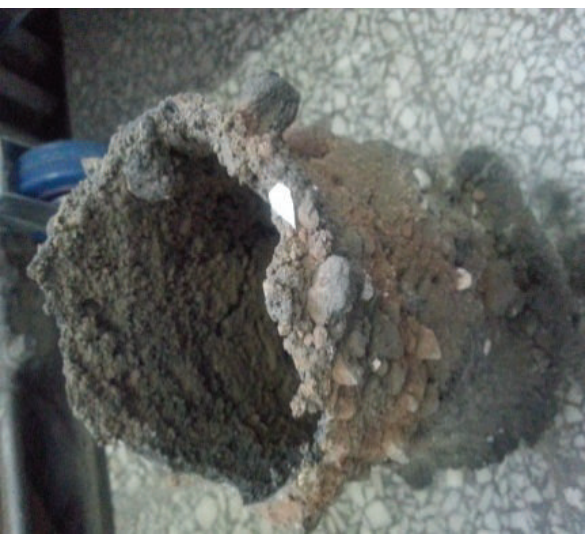

(d)

Figure 6: Experimental photos of the glass-like casing, (a) and (b) composition used in granite, heating up to $700^{\circ} \mathrm{C}$, and (c) and (d) composition used in soil, heating up to $700^{\circ} \mathrm{C}$.

on the composition that is intended for glass-like casing. Meanwhile, the addition of QS can boost the properties of the compositions by compressing its interconnected pores, lowering the overall porosity rate.

\section{Conflict of Interests}

The authors declare that there is no conflict of interests regarding the publication of this paper.

\section{Acknowledgments}

The authors gratefully acknowledge the support by the Beijing Organization Department Outstanding Talented Person Project (no. 2013D009015000002), the Beijing Higher Education Young Elite Teacher Project (Grant no. YETP0645), the Fundamental Research Funds for the Central Universities (no. 2652015), and the National Natural Science Foundation of China (no. 51272241). Meanwhile, great thanks also go to former researchers for their excellent works, which give great help for the academic study.

\section{References}

[1] H. Zhu, Q. Liu, J. Deng, G. Wang, and J. Liao, "Rock-breaking mechanism of rotary-percussive drilling," Journal of Basic Science and Engineering, vol. 20, no. 4, pp. 622-631, 2012.

[2] D. E. Armstrong, J. S. Coleman, B. B. Mclnteer, R. M. Potter, and E. S. Robinson, "Rock melting as a drilling technology," Los Alamos National Laboratory Report LA-3243, Los Alamos National Laboratory, 1962.

[3] G. E. Cort, S. J. Goff, and J. C. Rowley, "The rock melting approach to drilling," in Proceedings of the Energy-Sources Technology Conference and Exhibition (ETCE '94), p. 280, American Society of Mechanical Engineers (ASME), New Orleans, La, USA, 1994.

[4] S. K. Garg and J. Combs, "Slim holes for geothermal exploration and reservoir assessment in Japan," GRC Bulletin, vol. 23, pp. 89-96, 1994.

[5] X.-F. Wang, Z.-P. Zhang, and C. Chen, "A new drilling technique-subterrene drills," Geotechnical Engineering Technique, vol. 17, no. 2, pp. 123-125, 2002.

[6] L. U. Chun-hua, W. U. Xiang, and W. Qiang, "Study on hot-melt sidewall strengthening technology," Geology and Exploration, vol. 48, pp. 1034-1038, 2012. 
[7] A. Christogerou, T. Kavas, Y. Pontikes, S. Koyas, Y. Tabak, and G. N. Angelopoulos, "Use of boron wastes in the production of heavy clay ceramics," Ceramics International, vol. 35, no. 1, pp. 447-452, 2009.

[8] D. Jiang, L. Cui, Y. Zheng, and X. Jiang, "Effects of thermal cycling on the temperature memory effect of TiNiNb alloy," Journal of Materials Engineering and Performance, vol. 19, no. 7, pp. 1022-1024, 2010.

[9] R. W. Cahn, "Aluminium-based glassy alloys," Nature, vol. 341, no. 6239, pp. 183-184, 1989.

[10] A Preparation and Study on High Expansion Coefficient Glass Ceramics of $\mathrm{Li}_{2} \mathrm{O}-\mathrm{ZnO}-\mathrm{SiO}_{2}$ System, vol. 27, Shan Dong Ceramics, 2004.

[11] R. V. Manukyan and N. S. Davydova, "Use of waste in the ceramics industry," Glass and Ceramics, vol. 53, no. 7-8, pp. 247248, 1996.

[12] A. Escardino, J. Garcia-Ten, and C. Feliu, "Kinetic study of calcite particle (powder) thermal decomposition: part I," Journal of the European Ceramic Society, vol. 28, no. 16, pp. 3011-3020, 2008.

[13] J. Liebault, J. Vallayer, D. Goeuriot, D. Treheux, and F. Thevenot, "How the trapping of charges can explain the dielectric breakdown performance of alumina ceramics," Journal of the European Ceramic Society, vol. 21, no. 3, pp. 389-397, 2001.

[14] B. Cicek, A. Tucci, E. Bernardo, J. Will, and A. R. Boccaccini, "Development of glass-ceramics from boron containing waste and meat bone ash combinations with addition of waste glass," Ceramics International, vol. 40, no. 4, pp. 6045-6051, 2014. 

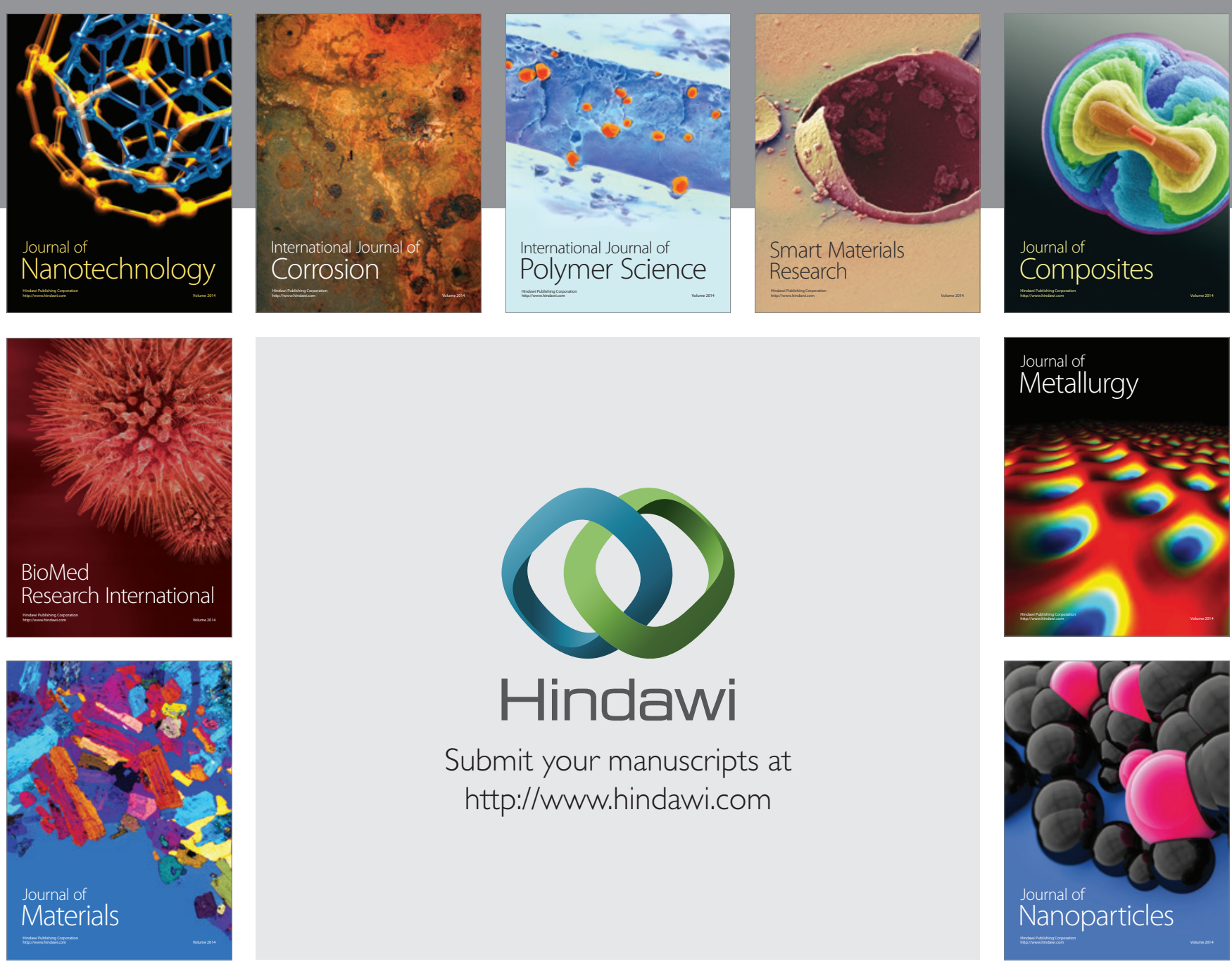

Submit your manuscripts at http://www.hindawi.com
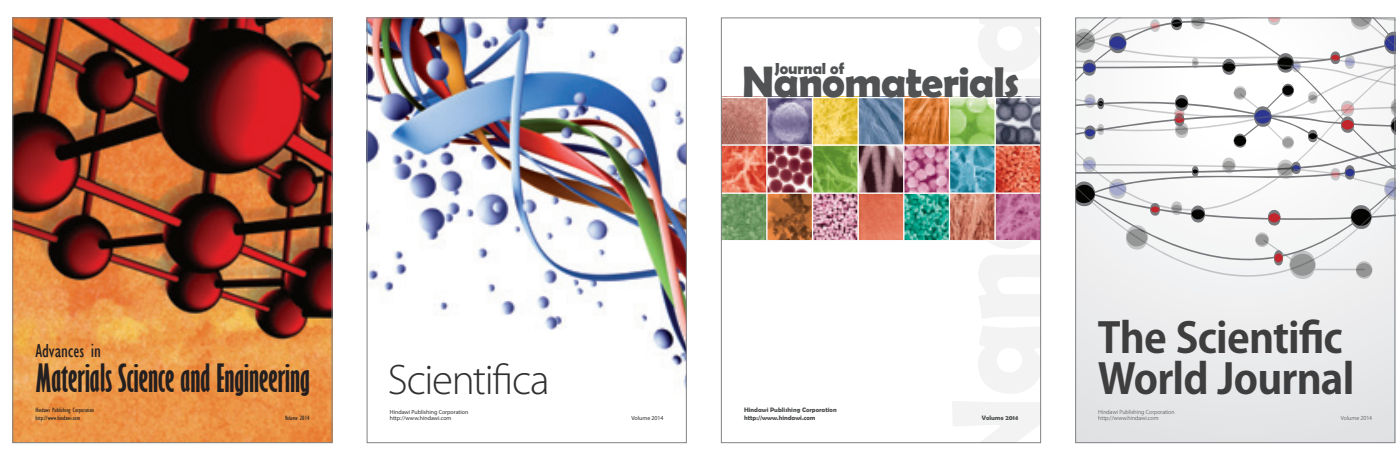

\section{The Scientific World Journal}
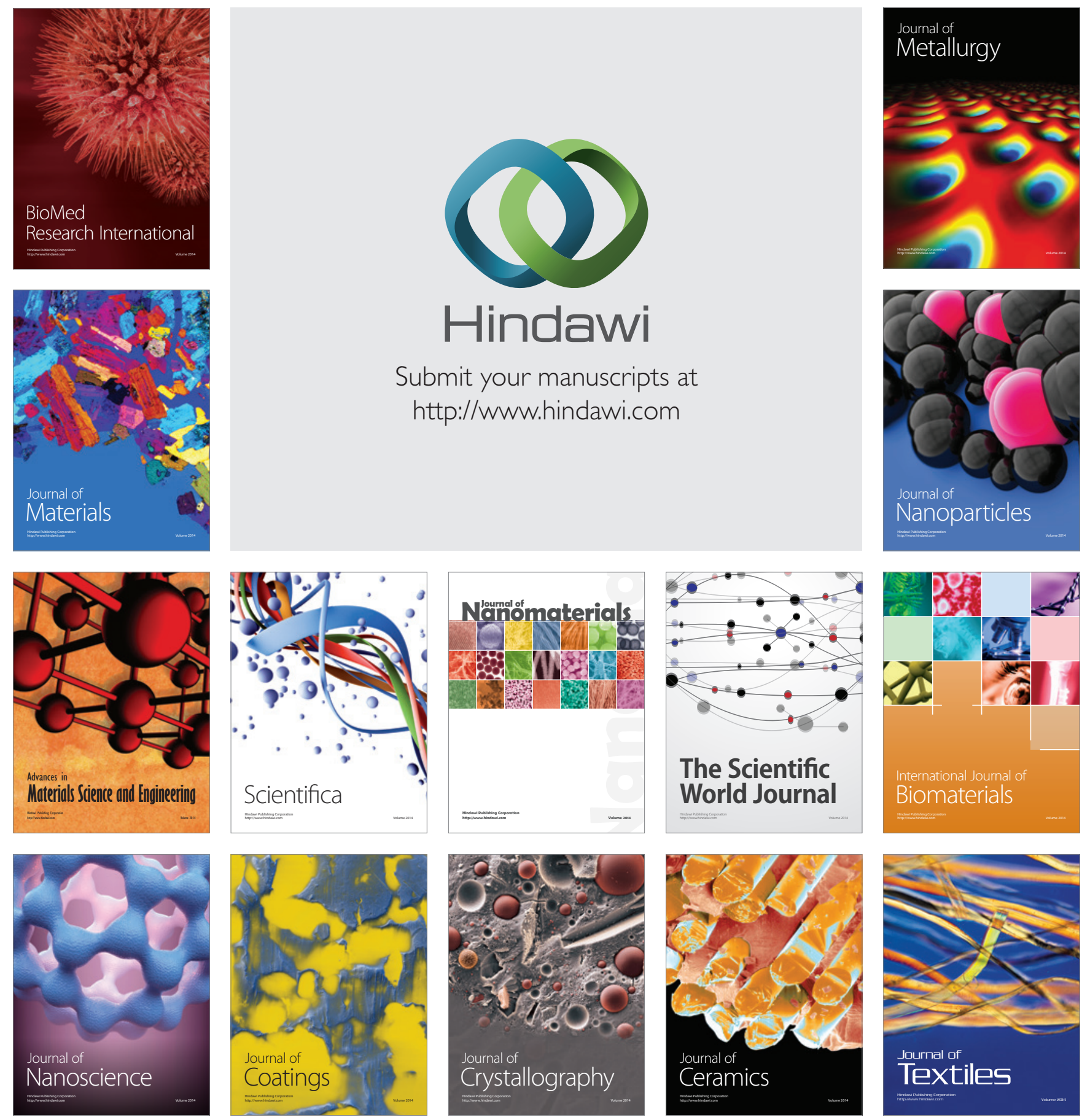